\title{
Panel Discussion: Understanding Students' Narratives of Grand Challenges Scholars Program as a Nexus between Liberal and STEM Education
}

\author{
Dr. Yevgeniya V. Zastavker, Franklin W. Olin College of Engineering
}

Yevgeniya V. Zastavker, Ph.D., is an Associate Professor of Physics at Franklin W. Olin College of Engineering and a recent Director of the Research Institute for Experiential Learning Science at Northeastern University. She earned her B.S. degree in Physics from Yale University in 1995 and her Ph. D. degree in Biological Physics from MIT in 2001. Dr. Zastavker's research interests lie in the field of STEM education with specific emphasis on innovative pedagogical and curricular practices at the intersection with the issues of gender and diversity. With the goal of improving learning opportunities for all students and equipping faculty with the knowledge and skills necessary to create such opportunities, Dr. Zastavker's recent work involves questions pertaining to students' motivational attitudes and their learning journeys in a variety of educational environments. One of the founding faculty at Olin College, Dr. Zastavker has been engaged in development and implementation of project-based experiences in fields ranging from science to engineering and design to social sciences (e.g., Critical Reflective Writing; Teaching and Learning in Undergraduate Science and Engineering, etc.) All of these activities share a common goal of creating curricular and pedagogical structures as well as academic cultures that facilitate students' interests, motivation, and desire to persist in engineering. Through this work, outreach, and involvement in the community, Dr. Zastavker continues to focus on the issues of women and minorities in science/engineering.

\section{Ms. Abigail M Fry, Olin College of Engineering}

Abby Fry is a second-year student at Olin College of Engineering majoring in Electrical and Computer Engineering.

\section{Ms. Holly Nguyen}

Holly Nguyen is a Master's student at Worcester Polytechnic Institute (WPI), studying Computer Science. She completed her Bachelor's at WPI with a major in Computer Science and a minor in Business.

\section{Gretchen Rice, Olin College}

Gretchen is originally from Maine and plans to graduate from Olin College in May 2020. Outside of classes and GCSP, Gretchen is president of Olin's A Capella group and works as a Resident Resource, a teacher's assistant, and a tour guide.

\section{Sydney Ross, Lawrence Technological University}

Sydney Ross is a first-year student at Lawrence Technological University (LTU). She is majoring in Computer Science with a concentration in Scientific Software Development.

\section{Mr. Sebastien Zenzo Selarque, Rochester Institute of Technology (CET)}

Sebastien Selarque is a fifth-year Electrical Mechanical Engineering Technology student at the Rochester Institute of Technology. He also works for Engineers for a Sustainable World, a not-for-profit organization, in order to effect social and environmental betterment through technology.

\section{Bridgit Spies}

Bridgit Spies is a second year student at RIT majoring in chemical engineering and minoring in environmental studies.

\section{Ms. Margarite Vaccaro}

Margarite Vaccaro graduated from Worcester Polytechnic Institute in May, 2018 with a degree in biomedical engineering and a minor in business. She currently works as an engineer in the medical device industry in the greater Boston area and absolutely loves it! 
Dr. Jason Barrett, Lawrence Technological University

Assoc Prof of History and Humanities Dept Chair; Grand Challenge Scholars Program Director

\section{Ms. Sarah Aileen Brownell, Rochester Institute of Technology}

Sarah Brownell is the Director of the Grand Challenges Scholars Program and a Lecturer in Design, Development and Manufacturing for the Kate Gleason College of Engineering at the Rochester Institute of Technology. She works extensively with students in the multidisciplinary engineering capstone design course and other project based elective courses, incorporating human centered design, participatory development, and design for development themes. She was a co-founder of the non-profit Sustainable Organic Integrated Livelihoods (SOIL) which promotes ecological sanitation in Haiti.

\section{Dr. Matthew Marshall, Rochester Institute of Technology (COE)}

Matthew Marshall is Associate Dean and Associate Professor in the Kate Gleason College of Engineering at Rochester Institute of Technology. He received a Ph.D. in Industrial and Operations Engineering from the University of Michigan in 2002. He is director of the Human Performance Laboratory at RIT and his research interests include the biomechanics of sign language interpreting and the ergonomic design of consumer products.

\section{Prof. Karen Kashmanian Oates, Worcester Polytechnic Institute}

Karen Kashmanian Oates A nationally recognized consultant, scientist, science educator, and higher education leader, Dr. Oates joined WPI from the National Science Foundation, where she had been serving as deputy director of the Division of Undergraduate Education. At the NSF, Karen managed a budget of over \$380 million and a staff of more than 35 charged with supporting innovative programs to strengthen undergraduate and graduate education and helped revitalize American entrepreneurship and competitiveness. As the inaugural Dean of Arts and Sciences, Karen brings a variety of perspectives on faculty development, career and executive counseling, leading change and setting a collaborative culture as well as service learning and business-higher education partnerships. Among the honors she has received are the Bruce Albert's Award, presented by the American Society to Cell Biology for excellence in science education reform, and the Distinguished Public Service Award, the highest civilian honor presented by the City of Harrisburg Pennsylvania. In 2012, she was inducted as a fellow into the prestigious American Association for the Advancement as Science Education fellow, and in 2016 a Sigma Xi distinguished lecturer. She now leads the University efforts for National Academy of Engineers - Global Grand Challenge Scholar program. After receiving her Ph.D. at George Washington University Medical Center in Biochemistry, she worked as a visiting scientist at the National Institutes of Health, National Cancer Institute Oncology and Hematology Division. She began her academic career at George Mason University, where, as associate dean for the newly established College of Integrated and Interdisciplinary Studies, she helped create George Mason's New American College environment. She later served as inaugural provost for the Harrisburg University of Science and Technology, where she established the National Center for Science and Civic Engagement and helped secure NSF funds for Science Education for New Civic Engagement and Responsibilities, SENCER which works to improve undergraduate STEM/STEAM education by connecting learning to critical civic questions. After 7 years as dean, Karen has returned to the faculty at WPI.

\section{David I. Spanagel, Worcester Polytechnic Institute}

David Spanagel is an Associate Professor of History in the Department of Humanities and Arts at the Worcester Polytechnic Institute, Worcester, Mass. He has been active as an innovator in curriculum and instructional approaches. He co-developed the Power the World course (one of the first Great Problems Seminar themes offered as part of WPI's First Year Experience) back in 2007. He has pioneered collaborative learning approaches in the history capstone projects that he advises for students completing the Humanities and Arts requirement. He worked with colleagues to overhaul and update WPI's history of science and technology course offerings in 2009, and again in 2017. Prior to acquiring a Ph.D. in the history of science at Harvard (1996), David's first graduate degree (an M.S. Ed.) involved academic 
research into mathematical problem solving techniques and pedagogy. Thus, his very first publication was an article on "Solving Extreme Value Problems Without Calculus," published in The Mathematics Teacher (1988).

\section{Dr. James J. Winebrake, Rochester Institute of Technology}

Dr. James Winebrake currently serves as the dean of the College of Liberal Arts at RIT. He works with the college's faculty, staff and students to advance education and scholarship in the social sciences, humanities, and performing arts, while also promoting interdisciplinary initiatives across RIT's nine colleges. One of his key initiatives is the integration of liberal arts and technology/engineering curricula at both the undergraduate and graduate levels.

Dr. Winebrake previously served as chair of RIT's Department of Science, Technology and Society/Public Policy and has earned international recognition for his research on issues related to the environmental impacts of transportation, including health risk assessments, life-cycle analysis of alternative fuels, and analysis of policies aimed at reducing emissions in the transportation sector. He serves or has served on several National Academies of Science committees, the New York State Energy Planning Board, and other professional boards related to energy and environmental technology and policy.

In 2010 Dr. Winebrake was awarded the RIT Trustees Scholar Award in recognition of his scholarly contributions in the energy and environmental fields. He has also received numerous other research and teaching awards during his career, including the Madison Scholar Award and the Outstanding Teacher Award while serving as a faculty member at James Madison University in Virginia.

Dr. Winebrake received his $\mathrm{PhD}$ in Energy Management and Policy from the University of Pennsylvania (Philadelphia, PA). He also holds a B.S. in Physics from Lafayette College (Easton, PA) and a M.S. in Technology and Policy from the Massachusetts Institute of Technology (Cambridge, MA).

\section{Alison Wood , Franklin W. Olin College of Engineering}

Dr. Alison Wood is an assistant professor of Environmental Engineering at Olin College of Engineering. She is a distinguished researcher in the fields of both water and sanitation, as well as a researcher and practitioner in using interdisciplinary thinking and approaches to solving environmental and sustainability problems. Dr. Wood is also pursuing her interests in the areas of equity and justice through education and engagement with context and values.

In addition to her teaching and advising duties at Olin, Dr. Wood serves as the Director of the BabsonOlin-Wellesley Three College Sustainability Certificate Program, the Director of Olin's Grand Challenge Scholars Program, on the Catalyst Board of the open source journal Murmurations, as a member of Olin's Sustainability Steering Committee, and as a member of Olin's Context and Ethics in Engineering Education Working Group.

After graduating from Harvard University with a B.A. in Dramatic Literature, Dr. Wood worked professionally in theater and wrote and recorded two musical albums. She then returned to school to study engineering, earning a B.S. in Civil Engineering from Rutgers University. Dr. Wood then went on to earn a Master of Science in Engineering in Environmental and Water Resources Engineering and a Ph.D. in Civil Engineering from The University of Texas at Austin, while working with the Austin chapter of Engineers Without Borders as a volunteer and project lead for a project in Peru.

She has published and presented on incentivizing decentralized sanitation and wastewater treatment, on sustainability of coastal community water and sanitation service options, as well as on integrating liberal arts and STEM education, currently through the vehicle of the Grand Challenges Scholars Program. She has co-designed workshops oriented toward educational change for Olin's Summer Institute and the joint Olin College-Emerson College event: Remaking Education.

Her love of learning was first fostered by an unusual elementary school education that was deeply interdisciplinary with a substantial arts curriculum, which has informed all her subsequent thinking about the potential for education to transcend conventional models. 


\title{
Panel Discussion: Understanding Students' Narratives of Grand Challenges Scholars Program as a Nexus between Liberal Arts and STEM Education
}

\begin{abstract}
In 2008, the National Academy of Engineering (NAE), in collaboration with leading international technological scholars, produced a report with a radically new vision for engineering in the $21^{\text {st }}$ century. Calling for "continuation of life on the planet, making our world more sustainable, secure, healthy, and joyful," this document inspired a global movement urging interdisciplinary thinkers, policymakers, and the general public around the world to come together to address challenges facing humanity. As a part of this global movement, academic institutions responded by creating a Grand Challenges Scholars Program (GCSP), an initiative that complements and extends engineering education to include knowledge, skills, attitudes, and behaviors necessary to solve grand challenges outlined in NAE's report.

The GCSP is a framework that defines five competencies (Talent, Multicultural, Multidisciplinary, Entrepreneurship, and Social Consciousness), development of which serves to prepare a student to address NAE's Grand Challenges. These five competencies necessitate a holistic approach to educating next generation global citizens, not just next generation engineers.

As the program continues to grow, increasing numbers of scholars delve into the questions pertaining to the effectiveness of GCSP on improving students' learning outcomes. However, not much is yet known about the ways in which students, both engineering and non-engineering, make sense of the ways in which GCSP supports their holistic growth and development into global citizens of tomorrow.

Through this panel discussion and paper, we bring together GCSP Scholars from four different institutions funded by the Teagle Foundation to explicitly bridge liberal arts and STEM education through GCSP. The participating institutions - Olin College of Engineering (Olin), Lawrence Technological University (LTU), Rochester Institute of Technology (RIT), and Worcester Polytechnic Institute (WPI) - represent diverse academic and institutional cultures and are at different stages of GCSP development, with Olin being one of the founding GCSP schools and LTU being the newest addition to the national program. The panelists, both engineering and non-engineering majors as well as those early in their GCSP career and GCSP alumni, share their stories and critically reflect on the pathways which GCSP presented for them. Through their critical narratives, we show how the explicit bridging between liberal arts and STEM education within the four GCSPs enables Scholars to interrogate their personal selves and lead the way in
\end{abstract}


engineering education by engaging in the hard work of thinking about what it means to be human.

\section{Introduction}

In 2008, the National Academy of Engineering (NAE), in collaboration with leading international technological scholars, produced a report with a radically new vision for engineering in the 21 st century [1]. Calling for "continuation of life on the planet, making our world more sustainable, secure, healthy, and joyful," this document inspired a global movement urging interdisciplinary thinkers, policymakers, and the general public around the world to come together to address challenges facing humanity now and for the foreseeable future [1].

As a part of this global movement, institutions of higher education (and lately K-12) responded by creating a Grand Challenges Scholars Program (GCSP), an initiative that complements, enriches, extends, and broadens engineering education to include knowledge, skills, attitudes, and behaviors necessary for scholars of the future to solve grand challenges outlined in NAE's report. The GCSP is a framework that defines five competencies, development of which serves to prepare a student to address NAE's Grand Challenges:

1. Talent Competency: mentored research/creative experience on a Grand Challenge-like topic

2. Multidisciplinary Competency: understanding multidisciplinarity of engineering systems solutions developed through personal engagement

3. Viable Business/Entrepreneurship Competency: understanding, preferably developed through experience, of the necessity of a viable business model for solution implementation

4. Multicultural Competency: understanding different cultures, preferably through multicultural experiences, to ensure cultural acceptance of proposed engineering solutions

5. Social Consciousness Competency: understanding that the engineering solutions should primarily serve people and society reflecting social consciousness [2].

Defined in this general and non-prescriptive way, the five-competency framework allows each institution to craft its own approach to designing and implementing GCSP and allows for student development that is aligned with institutional priorities and culture.

This framework aspires to serve as a holistic scaffolding for educating next generation global citizens, not just next generation engineers. As the NAE states, "addressing the NAE Grand Challenges will require the efforts and talents of many graduates educated in a range of engineering and non-engineering disciplines." As such, "the goal of each institutional [GCSP] is 
to prepare students for the multicultural, multidisciplinary, entrepreneurial, socially conscious global engagement needed for $21^{\text {st }}$ century engineering" [3].

It has been a decade since the NAE's seminal report and the inaugural Summit on the NAE Grand Challenges for Engineering at Duke University, where the NAE moved to endorse the GCSP as an educational supplement to engineering programs [2]. As of April 2019, worldwide, 71 universities have adopted the Grand Challenges Scholars Program on their campuses with close to 100 programs currently under development. Furthermore, the GCSP has moved into community college space and has been adopted within several K-12 school curricula. Today, GCSP has become a grassroots educational movement driven by a vision of what a holistic engineering education may be [1].

As the program continues to grow, an increasing number of policy makers, funding agencies, as well as academic and industry leaders begin to raise questions pertaining to GCSP efficacy and outcomes - those expected and potentially unexpected ones. Who are the GCSP Scholars? How are they different than engineering graduates from non-GCSP institutions? What do they bring to the table that distinguishes them? Unfortunately, to date, there is little research to address these difficult questions. Most of the published materials focus on descriptions of institutional GCSPs or how to design them $[4,5]$, delve into questions pertaining to design and implementation of GCSP-relevant curricula [6], assess impact of incorporating Grand Challenges (GCs) into general engineering courses [7,8], and describe students' emerging understanding of becoming a GC Scholar at a single institution, including development of their engineering identity [9]. To our knowledge, there is one multi-institutional study to date that attempts to understand the breadth of institutional GCSPs and how their structures may be affecting student learning outcomes and experiences [10]. However, not much is yet known about the ways in which students, both engineering and non-engineering, across multiple institutions make sense of the ways in which GCSP supports their holistic growth and development into global citizens of tomorrow.

What do we mean by a holistic growth of engineering students? What do we mean by "global citizen?" As Carl Mitchell points out, the ultimate Grand Challenge of engineering is that of selfknowledge, , a challenge that requires "thinking reflectively and critically about the kind of world we wish to design, construct, and inhabit in and through our technologies" [11]. This Grand Challenge, or rather, competency, implicitly undergirds the GCSP framework and necessitates careful nurturing and assessment of our students. It is also the competency, development of which positions GCSP scholars to grow beyond the "technologist" boundaries and become global citizens who "think about not just the human condition but the techno-human condition: our responsibility for a world, including ourselves, in which the boundaries dissolve between the natural and artificial, between the human and the technological, [so as] to learn not simply to affirm engineering prowess but to limit and steer our technological action" [11]. And 
for that, we argue, it is critical to bring together liberal arts and STEM education and understand the nuanced ways in which this integration supports GCSP scholars' development.

This panel discussion aims to begin uncovering the role of GCSP in this holistic development of students into global citizens. We do so by sharing critical narratives of selfhood development of GCSP Scholars from four collaborating institutions - Olin College of Engineering (Olin), Lawrence Technological University (LTU), Rochester Institute of Technology (RIT), and Worcester Polytechnic Institute (WPI). Funded by the Teagle Foundation to explicitly bridge liberal arts and STEM education through GCSP, these four colleges and universities represent diverse academic and institutional cultures and are at different stages of GCSP development with Olin being one of the founding GCSP schools and LTU being the newest addition to the national program [12].

In this paper, the panelists, both engineering and non-engineering majors as well as those early in their GCSP career and GCSP alumni, share their stories and critically reflect on the pathways which GCSP presented to them. Although explicitly the scholars respond to questions relevant to the development of various GCSP competencies, implicitly their narratives are about their growth and evolution into global citizens, those who are not afraid to interrogate social norms and stand up to power structures, those who leverage their religious or philosophical standing to make sense of their newly found techno-human condition, and those who begin to ponder existential questions related to life and living. At the core, the panelists and co-authors of this paper tackle the difficult task of "knowing thyself," and that of unpacking and practicing their "selfhoods" [13]. As such, their narratives are works in progress, a snapshot of where they are today, and a rough draft of where they have been and where they may go. This paper is meant to raise more questions than provide answers and we expect that the panel discussion will allow opportunities for audience members to ponder together about the role of GCSP in students' development and the ways in which the explicit bridging of liberal arts and STEM in the GCSPs of the Teagle-funded team may better position students to do so.

\section{Students' Narratives}

\section{Gretchen Rice '20, Olin College of Engineering (Olin)}

My name is Gretchen Rice; I am a robotics engineering student from Maine attending Olin College and will be graduating in May of 2020. I chose Olin for the community, but also for their passionate mantra, "Engineering starts with people and ends with people." This mantra painted a new picture of engineering for me as I had previously believed engineering was about using math to make cool things. In fact, I originally wanted to be an engineer to continue my passion for robotics that I had developed over 9 years on a robotics team. But, this mantra created an 
almost invisible itch in the back of my mind that has slowly grown into the driving factor of me becoming an engineer.

My first real experience with people in engineering was my second semester at Olin in a class called Engineering for Humanity. In this class we worked with local community members to identify a problem or challenge they may be facing and design an appropriate solution not just for them, but importantly, with them. This was the first class that made me reflect and think about what I wanted to do as an engineer. I enjoyed working with people and helping to improve their lives in the class, but still had this strong love and draw towards robots. My fourth semester I took a class called User Oriented Collaborative Design (UOCD) where I worked with a "user group." Again, I was working directly with the people to try to find out who they were before trying to solve anything. I was starting to question if I had chosen the right major, since robotics seems to be so removed from people. However, I decided to stick with it, I was still really intrigued by robots! I just also liked people.

Around the same time I was in UOCD, I joined GCSP. My joining couldn't have been at a better moment, as I was just beginning to question my path as an engineer. It seemed that this organization focused on asking important questions about engineering, such as why do engineering? How does engineering work affect the world? I joined the GCSP steering committee hoping it would help me grapple with these questions and find a direction and purpose in the robotics engineering I planned to do.

In the summer after my fourth semester I packed up and moved across the country for an REU (Research Experience for Undergraduates) in a robotics lab where I was working with graduate students writing code. I still had these thoughts and questions about my purpose and direction, but I was excited about robots and was hoping this REU would deepen my love and revive my passion for the computational robotics path I was hoping to go down. I had a lot of space and time to think that summer. During that time I began to delve deeply into the space of women's health and empowerment. Eventually, it started to be the only thing I thought about; I was realizing I did not want to work on a computer my whole life writing code for robots. I wanted to be in the world, talking and designing with people. After that summer, I came back to Olin with a completely different mindset; I was no longer looking forward to the computational robotics class I had been so excited about in the spring, I didn't want to do the robotics work I was set to do, I just wanted to take action on my newly found passion.

Subsequently, my fifth semester at Olin was a developmental one for me and it was significantly backed by GCSP. I was, clearly, questioning my entire path through engineering, but our GCSP steering committee meetings gave me a space and community within which to reflect more about the issues I care about, such as women's health, the environment, and education. I was beginning to care a whole lot more about politics and the news, things I had consciously avoided in the past because they gave me anxiety. It was scary to think about such large, often negative, issues alone 
when I didn't feel like I could do anything to help. Discussing these topics in the meetings gives me an opportunity to voice my thoughts and feel a sense of community and the security that comes with that.

The GCSP steering committee became my sounding board and encouraged me last semester to be brave and dig deeper into what is really important to me and why. During our meetings, I was able to talk with the group of other GCSP'ers about menstruation huts still being prevalent throughout the world, about waste produced by menstruation in the developed world, and about the lack of equity and equality in education systems. I was becoming more aware of the severity of some of the challenges we are facing as a society, such as global warming and public health, and gaining more of an understanding and confidence to talk about these issues outside of the meetings.

This semester, I used GCSP as a jumping board for action. I wanted to help create spaces like our GCSP meetings for other students: spaces where they can discuss and learn about issues that strike them as important in the world. I was also able use this space to expand on my passions of women's health and empowerment to share the abhorrent truths I have learned through reading, thinking, and discussing with other GCSP'ers. We ran an activity at a community-wide event this semester where we asked community members to think about what inspired them and what traits an engineer who inspires would have. It was great to help spark ideas and discussion around other people's passions through GCSP.

This whole transformation I have gone through in the past year or so has helped me to begin my journey of development into a global citizen. I have done a lot of reading about people who come from different cultures, traditions, and situations than myself. I have learned about the problems surrounding menstruating prisoners and people who are homeless in America. And I have also learned about the lack of menstrual education and continued existence of menstrual shame. I have been building up my knowledge base and compassion for others which I believe is the first step to becoming a global citizen. The next step is action, whether that be sharing of knowledge with others, joining a political march, or starting a movement. I have started taking action by talking to people, but this is only the tip of the iceberg. I had been hoping to spend this summer at a non-profit that helps to empower women or is in the women's health field. Instead, I have decided to test the waters in the engineering field, one last time. This summer I will be doing another REU at Harvey Mudd. This summer I will not be working in a field robotics lab though, I will be experiencing true human robot interaction research. I am excited to use this summer to see, if I incorporate humans with robots, do I enjoy the field more? Since I will not be working at a non-profit, I do hope to find a volunteer opportunity this summer for me to further explore this passion in the women's empowerment and health field.

GCSP, for me, has been an incredible community that has helped me grow. In my last year at Olin, GCSP is going to continue to be this support for me and be a place for me to launch 
actions. GCSP has helped me become more confident in myself as well as helped me develop these competencies that will help me become a global citizen and, in turn, a person I am proud to be. From a lost engineer to a humanist with engineering skills - that is what my journey through GCSP has been about.

\section{Abby Fry '21, Olin College of Engineering (Olin)}

My name is Abby Fry. I'm a current sophomore at Olin College of Engineering in Needham, Massachusetts and majoring in Electrical and Computing Engineering. I'm originally from Overland Park, Kansas, and am a proud Midwesterner. Outside of engineering, I'm particularly interested in public policy/government. For fun, I like to spend time outside, read, rock climb, and try to cook new things.

I was drawn to engineering because I liked the idea of problem-solving with a purpose. I had always liked doing and trying new things and I was confident by the end of middle school that I was going to be an engineer. I did the usual high school course load of math and science but I also found my love of public policy on my school's debate team. Being a competitive debater meant that I spent hours after school researching everything from the international oil marketplace to domestic surveillance. Being exposed to such a variety of topics helped me put together a worldview and begin to understand the complexities of attempting to change the status quo. Those complexities solidified for me that any problem-solving I wanted to do in the technical realm would also need to be paired with multiple other considerations (e.g., policy implementation, cultural shifts, etc.) to be successful. That realization caused me to look for opportunities beyond the already diverse Olin curriculum and to consider GCSP as a way of engaging in thinking about global challenges and opportunities they present. I had heard of GCSP prior to getting to Olin but had little idea what the program actually meant on the ground. I initially became involved by going to a series of GCSP-hosted conversations with faculty members. These conversations so profoundly touched me that I eventually joined not just the program but also the GCSP steering committee.

Nestled in the suburbs of Boston., Olin is often considered to be a bubble. With fewer than 90 students in each graduating class, very few cultures have strong representation in the student body and it can be a challenging place to expand your worldview. Many students choose to study abroad during their junior year but for those of us who are still on campus, there aren't many opportunities to engage with other cultures, particularly implied in the definition of Multicultural Competency within the GCSP framework. Olin's GCSP steering committee, that includes students and faculty, made a decision that one of the ways in which we can address Multicultural Competency is in the design of a new GCSP course offering that focuses on how students should consider changing the world. Emphasizing the Multicultural Competency became a critical thing we wanted to address in the class. Although there is no substitute for direct engagement with other cultures, we, as a community, wanted to find some way to include the experience for 
scholars while they are still on campus. And, as a community, we approached the course design faculty, students, and staff working together to co-design an experience for all Oliners, not just GCSP scholars, that fills an important educational gap.

We started our co-design process by considering the intention of the Multicultural Competency, which is to help students consider how cultural norms impact solutions to complex challenges, including the Grand Challenges. In designing one of the assignments for the class, we were able to unpack the underlying principles of multiculturalism one step further. Critique of the 14 Grand Challenges often involves a consideration of who was included in the decision-making process about which specific challenges were to be included in the set of 14 . The prominence of the developed nations in this decision-making process is difficult to ignore. If there was going to be another attempt at compiling Grand Challenges that are of global importance, what cultures would need to be included in the conversation? Where would the talks need to take place? Is it even possible to create a comprehensive list that can account for the vast array of cultures impacted by global challenges? Having students consider these questions was a way to look at how cultural differences impact the decision-making process and how that could result in a different list of challenges. As an Oliner, I have this unique opportunity to both design a curricular offering and take it. In fact, I intend to take this class later in my college career, and I am greatly looking forward to experiencing a deep dive into those questions, which will necessarily allow me to gain greater understanding of how multiculturalism should impact what we consider to be global issues.

My participation in GCSP through the student steering committee and GCSP-hosted events has given me the opportunity to connect my engineering education to a larger worldview. The problems that we can choose to work on as engineers should be contextualized to the world we live in and I'm excited to use GCSP to keep making those connections.

\section{Sydney Ross '23, Lawrence Technological University (LTU)}

I am Sydney Ross and I am currently attending Lawrence Technological University (LTU) as a Computer Science major. I just finished my second semester and I am on track to graduate in 2023 with a Masters in Computer Science and a certificate in Engineering from participating in the GCSP. I am from a small town in Hartland MI that has a huge education system (my high school had the same number of students as my college). My soccer team shaped me into a determined person. Figure skating taught be how to think outside the box and helped me grow my creative instincts. And I was in way too many clubs; however, one specific experience allowed me to discover what my true passion is.

I was in a computer programming class and one of our assignments involved designing and coding a video game for a student with special educational needs to help with their comprehension and engagement in one of their classes. I ended up being partnered with a first- 
year student who had autism and cerebral palsy and was struggling with basic mathematical concepts, including telling time. During our first meeting, my peer, Jared (as I learned his name to be through the aid of his text-to-speech iPad), shared one of his favorite memories of trick-ortreating. Though you could not hear the excitement and joy in his voice, due to the robotic replication, it was written all across his face and stature: as he told me how his mother added a lighting bolt to his wheelchair, Jared's head was thrown back with laughter, his eyes twinkled as the fluorescent lights bounced off them, and a smile never left his face. I wanted to recreate this intense feeling of joy for him, so that every time he played the game I created for him, he could throw his head back and laugh even while learning. Given what I have learned about Jared, a Halloween-themed game seemed to make most sense. So, I programmed a haunted house where Jared would have to read clocks that appeared in order to get ready for trick-or-treaters. Then, in the later levels, once the trick-or-treaters arrived, he had to solve word problems using addition, subtraction, multiplication, and division, to determine how much candy to give the kids.

Two weeks later I nervously introduced my game to Jared. It needed to be great! It needed to be joyful! It needed to be just right for him! And when the moment came to unveil the game and Jared realized it involved Halloween, he cried. Those were tears of happiness. As Jared played, he squinted his eyes to see the problem better, and made an excited sigh of relief whenever he got a problem right. And he smiled as he played the game that I... I had created for him. At the end of the year, I learned that Jared had continued to play my game throughout the year, which contributed to his math grade improving. It was this experience of working with Jared that allowed me to get a sense of what I wanted to do with my life - to use technology to benefit society and the individuals within it. The real question was "how?" And, more specifically, how to do so while in college.

Once I got to LTU, one of my professors had mentioned the Grand Challenges Scholars Program, which seemed to align with my newfound goals. With the help from the faculty and in collaboration with my friend, I developed two project ideas that both related to my educational focus and would allow me to develop as a GCSP Scholar.

The first venue involves the Grand Challenge (GC) of Securing Cyberspace. I was immediately drawn to this Grand Challenge because of my love for crime shows, despite the obvious difference between Hollywood portrayals of cyber crime and the actual role of Cyberspace. Inspired by my past experience with Jared, I knew that to be successful I had to do rigorous research before deciding on a specific project within this Grand Challenge. I learned that the internet is made up of layers, but the average person only uses the top one, the Open Web. However, $90 \%$ of the internet is not easily accessed and most people do not know about it. This $90 \%$ is made up of the Deep Web and the Dark Web. The latter, a place of anonymity and secretive transactions, as I learned through my research, is a place where terrorists recruit members, sale of illegal products, like weapons and drugs, and human trafficking occurs, among 
other things. I also learned that a number of my friends use the Dark Web, specifically because they like the anonymity the Dark Web provides them. This is understandable. And yet, I felt uneasy about their online safety. And so the decision to pursue the Grand Challenge of Cyberspace Security was solidified - I wanted to understand how to create an environment that would be both safe (my design criterion) and anonymous (my friends' design criterion).

Using the information I learned from classes that are both in and outside my major (e.g., Psychology), as well as much independent research about the Dark Web, I have learned that in order for my algorithm to work, the information I need to track must be different than that used for tracking on the Open Web. Specifically, my algorithm will need to build an individual user profile, i.e., it will need to get to know a person without knowing who they are.

Amidst my involvement in the first project under the advisory of my professor, I was approached by one of my friends asking me to be a part of another Grand Challenge project aligned with the GC of Advancing Health Informatics. He has had a lot of health problems growing up and spent the majority of his early teen years in and out of hospitals. What was even worse, due to the hospitals' locations, he sometimes felt as though he was in danger in a very place where he was supposed to feel safe and secure in the knowledge that he would get better.

In hopes of eliminating potentially harmful events from occurring in places of public welfare, my partner and I are developing a new security camera with an intuitive scanning device. The scanner will be able to detect the relationship between movement and someone's weightdistribution to determine whether they are carrying a weapon. We intend for the scanner to also have a license plate reader and other unique features. Our initial designs are focused on locating the scanners in hospitals - an obvious place, given my partner's traumatic experiences. We then aim to implement our security system at K-12 schools and places of religion. These three general locations are purposefully selected for our project because they are the three "softest" targets for violence. We are trying to advance security because we are grieved and frustrated that mass shootings have become a trend in the current years. Coincidentally, or not, when my teammate and I were debating if there was actually a need for our project, we learned that Olympic figureskating pair Alexa Scimeca-Knierim and Chris Knierim, had dedicated their performance to the victims of the Parkland, FL shooting. Our system is important because we want to prevent tragic acts from becoming normal or unsurprising. And also I am excited to see how the engineering and development of this project will impact the world.

Although I am at the very beginnings of my college and GCSP experience, I feel that the program, through these two projects, is already shaping me into a global citizen. In today's socio-political climate being a global citizen means to be aware of the world around you and to be an active citizen. Thinking back to where this journey started, in my small town and big high school with a friend named Jared, I have realized that being a global citizen starts with 
understanding the world around you. Until I was assigned the project to help Jared, I regret to say that I had never thought about how the people around me live and what everyday struggles they face. In continuing this journey to become a true global citizen, the GCSP has helped me already to understand that my goals don't have to stay figments of my imagination. The program has given me the resources to expand my knowledge and the confidence to apply that information to better society. I believe this is due to my liberal arts and STEM education. Having lessons in both has improved my understanding of the people around me and society as a whole, while giving me the knowledge necessary to make an impact on the world. I want to help people - since working with Jared, that is all I want to accomplish in life. And now, thanks to the LTU's Grand Challenges Scholars Program, I feel like this is an attainable goal.

\section{Bridgit Spies '22, Rochester Institute of Technology (RIT)}

My name is Bridgit Spies, and I am a second-year chemical engineering major at RIT minoring in environmental studies. I am from Newtown, CT, where I grew up in the middle of a forest preserve, which allowed me to develop a deep appreciation for the natural world around me. Growing up in this small town surrounded by the wilderness I have watched my community struggle with what to do about environmental issues. Can we sell part of the town's preserve to a condo company in hopes of growing the local economy? Can we put solar panels on the town hall built in 1770? Should we ban plastic bags in grocery stores or plastic straws in restaurants? Many times, it seemed like a battle between saving the environment and preserving our way of life, as if the way in which we chose to exist was in opposition to the environment in which we chose to exist in. High school is when I first noticed and learned to pick sides. I joined climate advocacy groups and participated in trash clean ups and earth day celebrations, but it always seemed superficial with no tangible change. I tried advocating for a plastic bag ban, saying that we wouldn't have to pick up so much trash if we weren't handing it out for free in every store. After months of town meetings, it was decided that plastic bags were too fundamentally a part of the way we lived to be banned.

Around this time is when I discovered that my state congressman was a climate change denier. He was also my Driver's Ed teacher and told me he drove a Prius because he loved the gas mileage. I had tried and failed to help my town see that there were ways to live sustainably, but my Driver's Ed teacher showed me the only way people would ever be willing to live sustainably is if it came at a net benefit to them, if you disguise sustainability as simple technological progress designed to make life easier. So, I decided to join the engineering field to solve environmental problems. When I heard about the Grand Challenges Scholars Program, I applied thinking that it may provide me with the tools and connections necessary to make those changes a reality. 
In addition to my desire to change the way people looked at sustainable solutions, one draw of the GCSP is that the program is structured in a way that makes you rethink your comfort zone. For example, I have never been interested in business or entrepreneurship; in fact, the words business and entrepreneurship tended to scare me. However, through GCSP I have had to branch out of my comfort zone to develop the Business and Entrepreneurship Competency. This gave me the push I needed to register for the Simone Center's idea lab, a program in which a team of students in a variety of disciplines work together to solve a problem within the Rochester community. Working with the Center gives me an opportunity to explore the kinds of problems I want to solve and the ways in which I want to solve them. I can look at the the ways the community interacts with a problem and come up with a solution that is right for them, which is something I feel that I failed to do when trying to ban plastic bags in my community back home. I took my solution and tried to force it on others rather than listening and understanding people's ideas and frustrations. The more I thought about entrepreneurship the more I realized that it is really about finding new ways to solve problems. It is about creating alternatives to solutions that may have worked in the past but might not be best suited for the problem at hand today. Without the GCSP I don't think I would have come to the realization that entrepreneurship was a key aspect to a well-rounded multidisciplinary education.

Another aspect of GCSP that drew me in was the fact that while everyone in the program has similar goals and wants to solve similar problems, we all come from different places. For instance, I come from the middle of nowhere in a small town stuck in its ways, but through GCSP I have met people from big cities, whose communities change quickly. The fact that we can both sit in the same room and say that we want to solve the problem of climate change and industrial pollution is incredible and important. This sort of diverse and multicultural understanding is necessary when creating solutions to Grand Challenges. This approach also aligns well with my upbringing. My parents raised me with an appreciation of other cultures and backgrounds, taking me to festivals, encouraging me to learn new languages and always teaching me to keep an open mind. They taught me to understand that as a middle-class white girl from the US, I have an incredible amount of privilege. I need to recognize that I do not have all the answers, and instead of pretending to have them, I should listen and try to understand the experiences of others. I used to live right next to a large Latino community. After I learned to speak Spanish, it became so much easier to connect with and understand the people around me, specifically, their struggles within our community. From this experience I learned that it is impossible to solve problems without understanding them and, by extension, without understanding the people affected by them. This is particularly important for the environmental problems I want to solve since people are such a big part of those issues. GCSP has given me the opportunity to meet people with different understandings of the problems we face globally, just like spending more time with the Latino community afforded me a better understanding of the issues we faced locally. In both cases, these experiences provide more complete perspectives on problem-solving. 
Today people are more connected than ever, by technology, politics, and problems. It is now impossible for any nation to exist in isolation in a time of such constant connectivity. The GCSP recognizes that these kinds of global problems require a global perspective, one that comes from a multitude of voices from different backgrounds and different disciplines. Through my experiences both with GCSP and with activism in my own community, I have seen how effective a wide lens can be when solving problems that would have, in the past, been left to only scientists or engineers. I have learned that while an engineer or scientist can look at data and hard facts and come up with the most efficient solution to a problem, that doesn't mean anything unless there is the support of the community behind this solution. I have also learned that this community support can only come from listening and understanding the community on more than just a superficial level. My experience with GCSP has taught me to expand my worldview in a way that has been incredibly helpful when I look at solving Grand Challenges. These experiences, and this interdisciplinary view will provide me with a unique lens in my first industry experience on co-op next semester. I hope to take the tools and experience that GCSP has given me and apply that to problem solving in industry.

\section{Sebastien Selarque '19, Rochester Institute of Technology (RIT)}

My name is Sebastien Selarque. I'm a local of the Hawaiian island of Oahu. I'll be graduating this May from RIT with a B.S. in Electrical Mechanical Engineering Technology and an Immersion in Philosophy. I decided to pursue this unorthodox combination because I had a firm belief that the solutions to our world's most pervasive issues would require both technical and spiritual knowhow.

After my first year of college, I had the opportunity to study Tibetan Buddhist philosophy and art in Ladakh, a northern region of India, fulfilling my global competency for the GCSP. There I had experiences that have dramatically changed my life. The juxtaposition of what I encountered was staggering. I saw pain, joy, extreme poverty, extreme wealth, suffering and enlightenment. Mostly though, I saw people and through them I saw myself. I am not poor, persecuted, or disadvantaged and realized that it is not moral for me to be so blessed and not help others. I felt a call-to-action that I would eventually learn to actualize.

As I traveled from the city center of Old Delhi to the monasteries of Leh, I learned about Buddhism's three sacred jewels. The jewels represent the Buddha, the dharma, and the sangha. Most people are already familiar with Buddha, who is a historic and symbolic figure that represents enlightenment. The dharma is the teachings of Buddha, but in sanskrit the word holds many meanings and can be translated to mean "quality" or one's path of virtue. Lastly, the sangha is the community of fellow practitioners that strengthens and empowers one through their development and learning. If a sustainable and resilient Earth is my symbolic Buddha, and if my efforts to learn and do good is my dharma, then the Grand Challenges Scholars Program (GCSP) 
is my sangha. All three of these jewels are important, but I think the sangha is especially precious.

As a philosopher, I've come to a place in my mind and heart that is, existentially speaking, very dark. As an engineer, I want to solve the root causes of humanity's most pervasive problems. Honestly, that prospect is incredibly daunting and scary. What is the cost of failing to find a cure to antibiotic-resistant bacteria, or failing to address global water insecurity, or failing to halt and reverse climate change? It's in a reality such as this one in which my sangha - my community of passionate and game-changing peers and mentors - is like thousands of stars lighting up that darkness. GCSP equips me with the skills, the network, and the guidance that keep me determined and sanguine.

The reason I share this is because as Friedrich Nietzsche famously said, "He who has a why to live for can bear almost any how." Through my journey of travel, work, and education, I have found a passion for human betterment. Thus I have had more than enough drive to fulfil my social consciousness competency. Working for Engineers for a Sustainable World (ESW), a notfor-profit organization, has become a huge part of my life. As a member of my university's ESW student chapter I've lead an aquaponics project to help mitigate urban food insecurity and am working on a fruit dryer for rural Haiti to help stimulate economic development. Through GCSP, I have been able to deepen and broaden my understanding of sustainability challenges and solutions. For example, I'm actively working on a solar cell phone charging station installation for a homeless community in Rochester. At a recent GCSP regional event, I was able to learn and apply design thinking with Rochester community representatives who work with homeless shelters. This event allowed me to speak with experts who enhanced my perception on the issues with homeless communities, support organizations, and the overall low-income housing crisis. This awareness is important to me for both my work as an engineer and as humanitarian. It also reinforces my pursuit of opportunities such as joining ESW's leadership staff as International Development Coordinator, the Climate Reality Leadership Corps and the United Nations Youth Assembly.

I have been accepted into service as a Peace Corps education volunteer and have commited to 27 months of working in Guinea on a number of development projects. As a volunteer I will receive intensive language, teaching, and cultural sensitivity training. I hope to leverage my time in Guinea to both apply my hard-earned skills to benefit my community as well as further grow my capacity for implementing sustainable development locally and globally. Though my options for after Peace Corps are innumerable, one possible plan I hope to pursue is the Return Peace Corps Volunteers' Coverdell Fellowship and attend graduate school, likely to study the intersection of technology and public policy. 
The value of my sangha, the community that stands in solidarity and enriches my journey, is immeasurable. I'm excited about the future that the GCSP has helped prepare me for and I have no doubt that my fellow scholars will accomplish tasks as grand as the global challenges we all face.

\section{Holly Nguyen '18, Worcester Polytechnic Institute (WPI)}

My name is Holly Nguyen and I am a born and raised Californian, growing up in the heart of Silicon Valley until I began college at Worcester Polytechnic Institute (WPI). I graduated in May 2018 with a Bachelor's in Computer Science and a minor in Business. I am still attending WPI to pursue my Master's in Computer Science. Outside of academia I love to cook, bake, travel and watch Golden State Warriors basketball games.

From kindergarten through sixth grade I attended a Montessori school, the philosophy of which instilled in me such values as lifelong learning, responsibility, and independence, thereby enabling constant growth and perseverance. Throughout college, my values fueled my drive to learn and my determination to pursue research and extracurricular opportunities outside of the classroom. I had an unusual Grand Challenges Scholars experience in that I joined when I was a senior with three-quarters of my college career already complete. I was initially approached by GCSP advisors because my background indicated I had completed projects which had unintentionally developed skills within each GCSP competency. One of the aspects that drew me to the program was its competency-based framework, which meshed with the activities and academics I had already been involved in. I was also intrigued by the idea of the Grand Challenges - a set of vast and deeply rooted issues that no one would ever be able to solve. However, in further developing skills related to my Talent Competency throughout my senior year, my view of the Grand Challenges shifted and I began to realize how I could be a part of solutions as a global citizen by leveraging my values and education.

As a sophomore, I became a Clare Boothe Luce scholar, which is a program that allows women in science, mathematics, or engineering to pursue research as undergraduates with the guidance of a female mentor. This aligned with the Talent Competency and opened a door for a summer research experience working on a mobile sleep application designed to promote positive sleep behavior among college students. The project evolved to incorporate a new framework providing feedback and reminders to users about their sleep habits based on their personality. I continued this work as my Major Qualifying Project, which afforded me the opportunity to transform this conceptual research into a real web application, for which I needed to use the knowledge and skills from my computer science education.

The sleep project resulted in my collaborating with four WPI Professors (Drs. Ruiz, Wilson, Strong, and Djamasbi) to prepare a manuscript for the Hawaii International Conference on 
System Sciences. The opportunity to travel to Hawaii during senior year and present to an international community invested in furthering science was an enlightening experience because of its effect on my view of the Grand Challenges and my future academic career. One of the greatest benefits of the conference was the chance to listen and learn about the ways in which current global research was aligning with the ideas and values of the Grand Challenges. I remember being torn about which paper presentations to attend because so many topics caught my eye: fake news, social media and healthcare, privacy and technology, disaster relief, big data applications for diseases, and healthcare technology and analytics. I found one presentation focusing on hospital technology and process flow to be particularly intriguing and inspiring. The authors analyzed the effect of digitization of hospital healthcare systems and process innovations with the ultimate goal of utilizing technology to provide better patient care.

This hospital technology presentation fell under the same umbrella as the sleep project with a health-focused theme aided by technology. I began to understand how each piece of research under this umbrella could have far-reaching consequences for so many people that I may not ever personally know. This realization enabled me to see two things clearly. First, my academic ambition stemmed from my values but had largely been focused on problems relevant to my life, such as sleep. At the conference, I realized that I needed to broaden my perspective to expand the network of people I consider to be my community and the problems which I consider to be my own. This expansion of community and willingness to tackle problems highly relevant in other people's lives is what I believe it means to be a global citizen. A global citizen ultimately demonstrates caring and empathy when addressing Grand Challenges. Secondly, while the Grand Challenges are perhaps the most difficult global issues we face today as a society, there is already a global research community attempting to tackle them through sharing of ideas and collaboration. This gives me hope for future solutions.

Attending the conference inspired me to believe that there was something I could do to address even a small part of one Grand Challenge. I think this is one of the core GCSP goals: to motivate students to continue to work towards global solutions by using the skills which they develop throughout their formal education and within each competency. I personally decided to accomplish this by completing my Master's Thesis in Computer Science related to machine learning and the medical/health field.

I think it is easy for students to focus on the immediate problems: receiving good grades, searching for that first job, and participating in extracurriculars. However, the Grand Challenges Scholars Program at WPI urged me to think beyond this narrow perspective which constrained the issues I focused on. As a GCSP scholar, I may not have had the most conventional experience, but I benefited greatly by viewing my own college career through the lens of a new framework, thus prompting new personal and professional questions and encouraging new pursuits in graduate school. 


\section{Maggie Vaccaro '18, Worcester Polytechnic Institute WPI}

My name is Maggie Vaccaro and I graduated from WPI in May 2018 with a degree in biomedical engineering and a minor in business. I am originally from Marlborough, MA and continue to work in the area for Olympus Surgical Technologies America. From an early age, I knew I had an aptitude for math and science, but more importantly, I had a love for helping people. After suffering numerous sports injuries that led me to two ACL reconstructions and three meniscus repairs, I began examining how the knee brace I was wearing worked and how it was constructed. I was fascinated by it. From that point forward, it became my dream to develop medical devices to help patients recover from pain so that they are not forced to walk away from the things they love. With this goal in mind, I decided to pursue biomedical engineering at WPI where I knew I would receive a great technical education but also have the ability to participate in numerous projects in hopes of helping people.

With this passion for helping people through improving healthcare, I was intrigued when I was approached by the Grand Challenges Scholars Program's advisors at WPI during my senior year. By that time, I had already completed projects that specifically developed the competencies set by the National Academy of Engineering. After further research into the program, I found that my interests and career goals aligned with the cross-cutting themes of the program. The Grand Challenges Scholars Program competency requirements have never simply been checkboxes to mark throughout my college education but rather something I found myself completing because of my desire to make a difference and help people. While much of my work focused on Grand Challenge themes related to the healthcare field, it was the program's yearning to help students view problems and solutions through many different perspectives, rather than solely a technical angle, that intrigued me. In fact, one of the most impactful experiences of my undergraduate career was the two months I spent outside of the classroom, in a new country and a new community conducting interviews with locals to find a solution to a non-technical problem.

For those two months of my junior year at WPI, I traveled to Cuenca, Ecuador, as part of WPI's Interactive Qualifying Project. While there, I worked with three other WPI students and the Ecuadorian Government Department of External Relations to find better means of integrating North Americans into the country as Ecuador is becoming a popular place to retire due to the low cost of living. This migration trend has resulted in tensions among the native Cuencanos and North American retirees. Our task was to understand the source of these tensions as well as design and implement potential solutions. While this project was outside of the scope of both my biomedical engineering major and business minor, I was able to use the critical thinking skills learned in the classroom and apply them to this situation. Through interviews with both native Cuencanos and North American residents, researching past trends, and speaking with local business owners, my team was able to develop a framework that included eight core trends 
leading to tension between the two groups. In addition, we proposed solutions to mitigate identified issues and improve integration efforts. Our conclusion was that there are two distinct groups of retirees: those who engage with the community and become well integrated and those who, for whatever reason, become isolated and, therefore, not well integrated into the local society, which may develop into strained relationships with the native citizens. In an attempt to improve integration efforts, my team developed an acclimation pamphlet for incoming immigrants, with the goals of lessening the effects of cultural shock for newcomers and improving their integration into local society. We also developed two additional programs: a companion program and a volunteer program. Both programs were to encourage retirees to interact with the community and hopefully reduce some problems associated with retiring abroad, such as language acquisition and understanding cultural differences. I was proud to hear that the programs we initiated continued past our visit and were further developed by the Department of External Relations and WPI students two years after my project concluded. Not only did I help people but this unique experience provided an opportunity to learn how to work with an international government and with populations that differ drastically in terms of their business practices and cultural tendencies. The work we completed in Ecuador was done in response to an emerging trend resulting from recent scientific and technological development our world is becoming smaller and we are able to interact with many different cultures, countries and people in everyday life. As a result, we find ourselves needing to understand and adapt to different environments and customs, which is a prerequisite to becoming a global citizen.

Today, when reflecting on this experience, I think about who I was before that trip and who I am now. When choosing an international site to complete my Interactive Qualifying Project, my goal was to engage in a new culture, including learning a new language, as well as step outside of my comfort zone. What I actually took away from this experience was so much more than my two original goals. Before arriving to Cuenca, I had assumed tension amongst the retiree population was due to the natural shock of being an English-speaker in a Spanish-speaking country but I learned that language was not the only factor. Other aspects, such as culture, preconceived notions, generational differences, and lifestyle differences, played a major role in the tension amongst the two groups. Each of the 40 people I had the pleasure of interviewing and listening to brought new ideas, stories and opinions to our project. I learned about the importance of listening to all perspectives and how important it is to fully grasp someone's thoughts, opinions and feelings before arriving at a conclusion. Some discussed their personal life and how the influx of North Americans has affected them, their families and their businesses. Others shared their decision to move to Cuenca and the positive and negative experiences they encountered. By the end of the two months, I came to admire both those who had built their entire lives in Cuenca and those who had traveled to Cuenca in hopes of a bettering their lives. From this experience, I believe I gained an open mind and a strong desire to listen to all perspectives in order to develop the best solution. While it is important to be a technical problem solver, I will continue to use the non-technical skills I gained during my undergraduate 
experience when developing medical devices in the future. I plan on doing so by listening to everyone who may use or be affected by a product I design since understanding their needs will help in arriving at a solution that is both right and good for all constituencies.

Unknowingly at the time, what I also got out of this experience was development of the GCSP's multicultural competency. Without consideration of the cultural issues presented in the rising tension between native Cuencanos and North American immigrants, we would not have been able to identify core trends that lead to the original tensions between the two groups. Through this project, I was able to recognize that without either group better understanding the others' culture and community values, tensions would continue to arise.

I believe that being a participant in the GCSP allows students and alumni to develop into global citizens by challenging them to think of the impact they are having on their local communities and on the global society, not only from a technical engineering standpoint but from many perspectives. While in the classroom, I spent most of the time learning how to problem solve as an engineer, my time in Ecuador taught me that science, technology, engineering and math are not the only things critical in defining the problem and considering possible solutions. I believe that this is the type of realization a global citizen must have. For me, being a global citizen means constantly thinking about my actions and how they affect the world and people around me. Even more importantly, it means taking that next step and listening to how others view a problem, which is critical in developing a solution idea.

While my engineering degree prepared me to be an engineer in the healthcare industry, my undergraduate experience helped me find new passions and aspirations through development of non-technical skills that I believe were crucial in my journey to become a Grand Challenges Scholar. WPI provided opportunities to complete multiple projects that have developed creativity and understanding of research process, which includes viewing a problem in a multidisciplinary manner while on various project teams. In addition, I have a newfound passion for business, specifically in a start-up medical device environment and I hope to develop those skills in my current role. Lastly, through my work abroad, I have been able to develop a meaningful consideration of cultural issues and the need to address societal problems. While I may have developed these skills without the GCSP, I am grateful for my participation in the program as it has allowed me to reflect and expand on skills and lessons that I will carry with me in my career.

\section{Concluding Remarks}

Jerome Bruner (2002) argued that "it is through narratives that we create and re-create selfhood, that self is a product of our telling... [I]f we lacked the capacity to make stories about ourselves, there would be no such thing as selfhood" $[13,14,15]$. In many ways, this panel paper provides this exact opportunity for our GCSP scholars to "create and re-create" their selfhoods. However, 
we believe that it is the structure of our programs that underlies our students' ability to do so. Our hypothesis is that the GC scholars imbedded in Teagle Foundation-like GCSPs, where liberal arts and STEM education are explicitly bridged, may be better positioned to do the hard work of critical reflection that requires one to "position personal multiplicities within professional practice and re-position professional identity within personal subjectivities" [13]. We postulate that such explicit formal bridging within these GCSPs creates the necessary scaffolding for students to better gain "the [necessary] tools to reflect on themselves and their world-transforming enterprise" [11].

Citing Carl Mitcham again, "engineers, like all of us, should be able to think about what it means to be human. Indeed, critical reflection on the meaning of life in a progressively engineered world is a new form of humanism appropriate to our time - a humanities activity in which engineers could lead the way" [11]. Arguably, the students in these four GCSPs may be just doing this, leading the way.

\section{Post Scriptum}

As mentioned above, the scholars' narratives presented here are a temporal snapshot of where they are at the time of writing this paper and in the process of developing their selfhoods. These narratives are not intended to be final deliverables, nor are they intended to serve as data sources (just yet) for a rigorous research. Rather, these narratives are meant to serve as a rich source for all of us to interrogate the role of GCSP in developing students' ability to engage in critical reflection about themselves and the world around them and their growth into global citizens. As such, we leave the summative remarks to the panel, at which time we hope the audience will engage with the scholars in the process of critical reflection with ourselves and each other to allow for an opportunity to wonder together about the emergent themes and perform a kind of "just-in-time" synthesis.

\section{Acknowledgement}

The authors would like to acknowledge the Teagle Foundation for supporting this work.

\section{References}

1. National Academy of Engineering, "NAE Grand Challenges for Engineering ${ }^{\mathrm{TM}}$," $N A E$ Grand Challenges for Engineering. [Online]. Available: http://www.engineeringchallenges.org/File.aspx?id=11574\&v=34765dff. [Accessed: Feb. 1, 2019]. 
2. National Academy of Engineering, "About the NAE Grand Challenges Scholars Program," NAE Grand Challenges for Engineering. [Online]. Available:

http://www.engineeringchallenges.org/GrandChallengeScholarsProgram/14384.aspx.

[Accessed: Oct. 14, 2018].

3. National Academy of Engineering GCSP Steering Committee, "Proposing a GCSP at Your School," NAE Grand Challenges for Engineering. [Online]. Available:

http://www.engineeringchallenges.org/File.aspx?id=20142\&v=81204f97. [Accessed: Oct. 14, 2018].

4. J. P. Carpenter, C. White, C. Pionke, and K. Delfosse, "The National Academy of Engineering Grand Challenge Scholars Program: Changing the Conversation about Educating the Engineer of 2020," Proc. of the 2013 American Society for Engineering Education Annual Conference and Exposition, 2013. Available:

https://www.asee.org/public/conferences/20/registration/view_session?session_id=2312 . [Accessed: Feb. 1, 2019].

5. Y. V. Zastavker, J. P. Carpenter, C. K. White, T. M. Toole, "Starting a New Grand Challenge Scholars Program: What's? Why's? How's?” Proc. of the 2016 American Society for Engineering Education Annual Conference and Exposition, 2016. Available: https://www.asee.org/public/conferences/64/registration/view_session?session_id=5849. [Accessed: Feb. 1, 2019].

6. A. Trowbridge, H. Zhu, "Work in Progress: An Interdisciplinary Course Designed to Assist First-Year Students in Planning and Preparing for Success in the NAE Grand Challenge Scholars Program," Proc. of the 2017 American Society for Engineering Education Annual Conference and Exposition, 2017. Available:

https://www.asee.org/public/conferences/78/papers/19563/view. [Accessed: Oct. 14, 2018].

7. H. Zhu, A. Trowbridge, "Assessing the Impact of Incorporating the NAE Grand Challenges for Engineering as a Multidisciplinary Hands-On Design Project into the Introduction to Engineering Course," Proc. of the 2016 American Society for Engineering Education Annual Conference and Exposition, 2016. Available:

https:/www.asee.org/public/conferences/64/papers/14769/view. [Accessed: Oct. 14, 2018].

8. E. Fife, "Understanding the Impact of Engineering Through Engagement with the National Academy of Engineering Grand Challenges," Proc. of the 2017 Pacific Southwest Southwest Section of the American Society for Engineering Education Annual Conference, 2017. Available: https://peer.asee.org/understanding-the-impact-of-engineering-throughengagement-with-the-national-academy-of-engineering-grand-challenges.pdf. [Accessed: Feb. 1, 2019].

9. A. Trowbridge, T. G. Ganesh, D. K. Chen, and J. L. Roldan, "WIP: A Qualitative Analysis of Students' Emerging Understanding of Becoming a Grand Challenge Scholar-Engineer," Proc. of the 2017 American Society for Engineering Education Annual Conference and Exposition, 2017. Available:

https://www.asee.org/public/conferences/78/papers/20500/view. [Accessed: Oct. 14, 2018]. 
10. S. Donaher, C. L. A. Dancz, J. M. Plumblee II, A. S. Gordon, and K. Patel, "Reviewing the Current State of Grand Challenge Scholars Programs Across the United States," Proc. of the 2017 American Society for Engineering Education Annual Conference and Exposition, 2017. Available: https://www.asee.org/public/conferences/78/papers/18476/download. [Accessed: Feb. 1, 2019].

11. C. Mitcham, "The True Grand Challenge for Engineering: Self-Knowledge," Issues in Science and Technology, Fall 2014. Available: https://issues.org/perspectives-the-truegrand-challenge-for-engineering-self-knowledge/. [Accessed: Feb. 1, 2019].

12. A. Wood, S. Arslan, J. Barrett, S. Brownell, A. Herbert, M. Marshall, H. Morano, K. K. Oates, D. Spanagel, J. J. Winebrake, and Y. V. Zastavker, "Work in Progress: Transformation through Liberal Arts-Focused Grand Challenges Scholars Programs," Proc. of the 2019 American Society for Engineering Education Annual Conference and Exposition, 2019

13. G. Epstein and Y. V. Zastavker. (2017) Uneasy Stories: Critical Reflection Narratives in Engineering Education. In: Bairaktarova D., Eodice M. (eds) Creative Ways of Knowing in Engineering. Springer, Cham.

14. Bruner, J., 2002, Making Stories: Law, literature, life. New York: Farrar, Straus and Giroux. 15. Alsup, J., 2013, Teacher Identity Discourses: Negotiating Personal and Professional Spaces. New York, NY: Routledge. 